\title{
A Study on Anti-oxidative Activity of the Lithospermum Erythrorhizon Extracts for Application as a Cosmetic Ingredient
}

\author{
Hee-Jeong Park and Ki-Young Lee ${ }^{1 *}$ \\ Interdisciplinary Program of Perfume and Cosmetics, Chonnam National University, Gwangju 500-757, Korea \\ ${ }^{1}$ Faculty of Applied Chemical Engineering, Chonnam National University, Gwangju 500-757, Korea
}

\begin{abstract}
This study has assessed the anti-oxidative activities and cytotoxic effects of Lithospermum erythrorhizon ethanol extract and measured the effects of tyrosinase inhibition activities with a goal of estimating the usage of the medicinal plant as an ingredient of cosmetics. First, to perform a basic test on the extract, $\mathrm{pH}$ and UV-spectrum were measured. According to the measurement, the extract had control functions at $\mathrm{pH} 5.5$, and maximum absorbance occurred at 530nm. In particular, DPPH (1-1-diphenyl-2-picryl-hydrazyl)-inhibiting activity (IC50) and polyphenol content were $149.81 \mu \mathrm{g} / \mathrm{mL}$ and $51.28 \pm$ $2.52 \mathrm{mg} / \mathrm{mL}$ respectively. In addition, as extract concentration increased, tyrosinase inhibition activities improved as well. In raw 264.7 cell-based MTT assay, cell survival rates were $98 \%$ at $1000 \mathrm{ppm}$ and $153 \%$ at 100 ppm. Therefore, it's been confirmed that there is almost no cytotoxin. According to the test results above, it appears that the Lithospermum erythrorhizon ethanol extract would be effective in anti-oxidation and application as a cosmetic ingredient.
\end{abstract}

Key words - Lithospermum erythrorhizon, Tyrosinase, Cytotoxin, Anti-oxidation

\section{Introduction}

These days, with the increased percentage of aged in the population, in recognition that living quality is getting higher, studies on biological rhythms, the treatment of diseases, and preventing aging have been active (Choi et al., 2010). Previous studies on natural substances from various plants are as follows: the anti-oxidation and anti-inflammation properties of peach blossoms (Lee and Ahn, 2010), the antibiosis of gardenia on aerobic bacteria (Ryu and Jo, 2004), anti-oxidation and anti-inflammation properties of phellinus linteus (Cheon et al., 2006), white mulberry extracts (Cho et al.,, 2006), antioxidation and anti-inflammation effects of wild peach trees (Cha and Lee, 2004), bioactivity of cornus kousa (Kim et al., 2008), and the anti-oxidation properties of Platyphyllum extracts (Chang et al., 2011). With such trends and the need to be safe from chemical stimuli, we have a need to develop natural cosmetics and new products have been presented through increased interest in and demand for them (Sim et al., 2008). The skin which is in direct contact with cosmetics is

*Corresponding author. E-mail : phj9525@hanmail.net roughly divided into the epidermis and the dermis. The epidermis protects our skin from physical and chemical stimuli and its $\mathrm{pH}$ is an important element in its chemical protection mechanism. Healthy skin has a $\mathrm{pH}$ of 5.5 and it is weakly acidic, with the exception of the armpit and the scalp. Such weak acidity causes the skin to change to being alkaline through washing or external stimuli and to lose its chemical protection ability (Lee et al. 2004). Therefore, most basic cosmetics have the ability adjust and hold the proper $\mathrm{pH}$, and to help the skin to optimally maintain a weak acidity. In particular, weakly acidic cosmetics have this function (Ha, 1999). Cosmetics are restricted by safety, stability, and usability. In order to see the possibility of natural substances or extracts used as ingredients in cosmetics, their bioactivity, safety, and functionality should be examined. Evaluating their anti-oxidation ability, whitening, and their influences on cytotoxicity is considered basic to predict the possibility of their use as ingredients in cosmetics.

Lithospermum erythrorhizon a plant of the Boraginaceae family with red-violet roots, is called Jicho, Jacho, Jageun, Jadan and grows perennially in the mountains of China and Japan as well as Korea (Cho et al., 1999). It has been used as 
a medicinal and dyeing plant in Korea and Japan. Medicinal uses are to promote blood circulation, alleviate fever, treat eczema, and urinary tract infections (Lee et al., 1998). The plants outer skin of its root is a red-violet color and contains shikonin, acetylshikonin, and isobutylshikonin which are derivatives of naphthoquinone (Ju et al., 2010), as well as allantoin, cyanoglucoside, fumaric acid, and succinic anhydride as naphthoquinone coloring materials (Yun et al., 1999). Also, studies on the effects of shikonin have been made focusing on its control of oxidation and reduction reactions and the promotion of recovery in wounds and burns, atopy dermatitis (Ju et al., 2010), and anti-bacterial effects (Bae, 2004). This study aims to look into the possibility of Lithospermum Erythrorhizon as an ingredient for cosmetics by exploring its properties of $\mathrm{pH}$, anti-oxidation, whitening, and cytotoxicity.

\section{Materials and Methods}

\section{Specimen production}

The Lithospermum erythrorhizon used in the study was purchased from Yeongduk, Gyeongsangbukdo Province, washed in running water, frozen rapidly to $-80^{\circ} \mathrm{C}$, kept frozen for 24 hours, freeze dried, and then ground. To observe the properties of the powder, it was retted with different solvents and its $\mathrm{pH}$ was measured. Also its absorption at each wavelength was observed. Fluids extracted after the ground powder was soaked in $70 \%$ ethanol at room temperature for 24 hours were filtered with a filtering bed (Whatman No.2) and the filtered fluid was concentrated in a vacuum evaporator and frozen. The powder extract concentrate was obtained using $100 \mathrm{mg} / \mathrm{ml}$ (DMSO:Ethanol=1:1). The extract was filtered with the use of a $0.2 \mu \mathrm{m}$ filtering membrane(Fig 1).

\section{Reagents and equipment}

The extract solvents for the $\mathrm{pH}$ test were Grade 1 reagents (Duksan Pure Chemical Co., Ltd., Ansan, Korea) N-hexane, chloroform, ethyl acetate, butanol, ethanol, D.W (Distilled water), dimethyl sulfoxide (DMSO). These were selected according to their degrees of polarity. The reagent used for anti-oxidation was 1-1-diphenyl-2-picryl-hydrazyl (DPPH), and the enzyme used to inhibit tyrosinase activity was mushroom tyrosinase. MTT formazan for the cytotoxicity test was purchased from Sigma (Sigma-Aldrich Chemical Co. St.Louis, MO, USA). Also used was a rotary evaporator( Rotavapor-R, Buchi Labortechnik, Flawil, Switzerland), a color difference meter (Minolta CR-300, CT-310, Japan), a pH meter (InoLab pH 730, Germany), a spectrophotometer (Shimadzu, JP/UV160A), and a cell incubator (MCO-15AC, Sanyo electric, Japan), ELISA Reader (BioTek, USA).

\section{Measuring the $\mathrm{pH}$ with different solvents}

Lithospermum erythrorhizon was frozen and dried to make a $5 \%$ sample and its $\mathrm{pH}$ was measured with a $\mathrm{pH}$ meter using a powdered sample. The glass electrode was already immersed in distilled water and the detector was washed with distilled water and the measurement was made at $25^{\circ} \mathrm{C}$.

\section{UV-spectrum measurement}

The measurement values of pigments the sample held were presented in a Lab Color Space according to the standards of the Commission Internationale de I'Eclairage (CIE). First, $1 \mathrm{~g}$

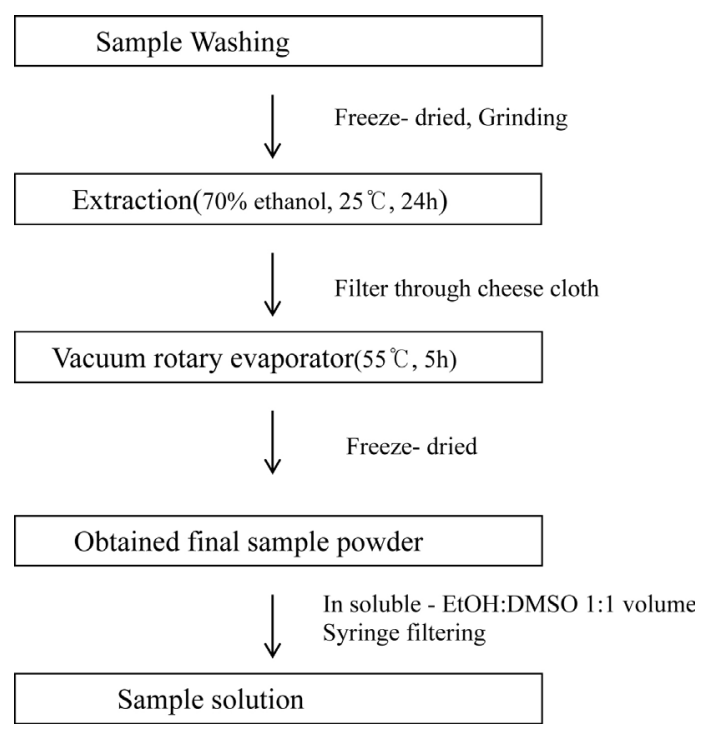

Fig. 1. The procedure for extraction from Lithospermum erythrorhizon. 
of the specimen was frozen, dried, and ground. It was spun in a centrifuge after it was dissolved in $20 \mathrm{~mL}$ of each solvent to extract the supernatant, and after a certain amount of time it was absorbed into a Whatman paper, the values of $\mathrm{L}, \mathrm{a}$, and $\mathrm{b}$ were measured with the use of a color meter (Minolta CR-300, CT-310). For UV-spectrum measurement (Shimadzu, JP/UV160A), $1 \mathrm{~mL}$ of supernatant extract was used and the absorption was measured between 200 and $700 \mathrm{~nm}$.

\section{Cell culture}

For the cytotoxicity test, RAW264.7 cells, a macrophage of a mouse, were purchased from the Korea Cell Bank and for a cell culture, DMEM growth medium containing 10\% FBS and $1 \%$ penicillin-streptomycin was used. The cells were cultured in $\mathrm{CO}_{2}$ incubators $\left(37^{\circ} \mathrm{C}, 5 \% \mathrm{CO}_{2}\right.$ incubator).

\section{Electron donating ability}

The electron donating ability was measured through the new Blois (1958) method. After $500 \mu \mathrm{L}$ of fluid sample of the different concentrations was mixed with $2 \mathrm{~mL}$ of DPPH in which 1,1-diphenyl-2 picrylhydrazyl (DPPH) was dissolved in ethanol with a concentration of $0.15 \mathrm{mM}$, it was vortexed for 10 seconds and reacted for 30 minutes at $25^{\circ} \mathrm{C}$ and its absorption was measured at $517 \mathrm{~nm}$. For EDA, the difference between absorptions of the test group and the control group was presented as a percentage. The $\mathrm{IC}_{50}$ value was used with concentrations which inhibit $50 \%$ of the oxidation from an EDA change curve according to the concentrations of the specimen. For a control group ascorbic acid was used.

\section{Total polyphenol compound}

The Total polyphenol amount measured through colorimetry with the Folin-Denis method (Swain et al., 1959). After the same amount of Folin-Denis solution was added to $1 \mathrm{~mL}$ of specimen with different concentrations for 3 minutes, $1 \mathrm{~mL}$ of $10 \% \mathrm{Na}_{2} \mathrm{CO}_{3}$ was added for 1 hour in a dark room and the absorption was measured at $700 \mathrm{~nm}$. Calibration curves were shown with gallic acid as a standard material.

\section{DOPA autoxidation inhibition assay (in vitro)}

To measure tyrosinase inhibitory activity, DOPA oxidase activity was measured with the use of an applied method developed by Moon et al. (2010). For DOPA oxidase activity, with L-DOPA as a substrate, absorption of dopachrome produced by tyrosinase was measured at $490 \mathrm{~nm}$. For the reactor, $120 \mu \mathrm{L}$ of L-DOPA (a solution dissolved in $8.3 \mathrm{mM}$, $67 \mathrm{mM}$ phosphate buffer [pH6.8]) as a substrate and $40 \mu \mathrm{L}$ of the specimen solution were placed into the 96-well plate. Then, $40 \mu \mathrm{L}$ of tyrosinase $(125 \mathrm{U} / \mathrm{mL})$ was added to it. After it was reacted at $37^{\circ} \mathrm{C}$ for 30 minutes, the activity was measured with a use of an ELISA reader at $490 \mathrm{~nm}$. For the control group, ascorbic acid was used to obtain an activity inhibitory rate.

\section{MTT assay}

To measure the cell survival rate, the MTT method was used. It measured the changes in color of yellow tetrazolium as it changed into purple fomazan by mitochondria enzyme of cells. $1 \times 10^{5}$ cells $/ \mathrm{mL}$ of RAW 264.7 cells were divided into $100 \mu \mathrm{L}$ and each of them was transplanted into a 96well tissue culture plate and cultured at $37^{\circ} \mathrm{C}$ in a $5 \% \mathrm{CO}_{2}$ incubator for 24 hours. To the cells cultured, the specimen solution of different concentrations was added and cultured for 18 hours, and then $50 \mu \mathrm{L}$ of $5 \mathrm{mg} / \mathrm{mL}$ MTT solution which was dissolved in a phosphate buffered solution (PBS) that was put into each well and cultured for 4 hours. After the cultures were completed, the supernatant was removed and $100 \mu \mathrm{L}$ of DMSO was put into each well and fomazan was dissolved and the absorption was measured at $570 \mathrm{~nm}$. Without the specimen solution added, the growth medium was added and the cell survival rate was measured based on the absorption of the control group.

\section{Results and Discussion}

\section{Measuring pH according to solvents}

To speculate on the possibility of the subject extract to be 
Korean J. Plant Res. 26(3) : 403 409(2013)

Table 1. $\mathrm{pH}$ measurement of Lithospermum erythrorhizon

\begin{tabular}{ccc}
\hline \hline Solvent & Solvent $\mathrm{pH}$ & Extract solution $\mathrm{pH}$ \\
\hline Hexane & $6.4 \pm 0.2^{* *}$ & $5.8 \pm 0.3^{* *}$ \\
Chloroform & $3.2 \pm 0.4^{* *}$ & $4.4 \pm 0.9^{* *}$ \\
E.Acetate & $2.6 \pm 0.3^{* *}$ & $3.1 \pm 0.6^{*}$ \\
Butanol & $5.1 \pm 0.3^{* *}$ & $4.5 \pm 0.5$ \\
Ethanol & $5.3 \pm 0.2$ & $5.8 \pm 0.4$ \\
D.W & $7.0 \pm 0.1^{* *}$ & $6.5 \pm 0.5^{* *}$ \\
DMSO & $9.5 \pm 0.2^{* *}$ & $8.4 \pm 0.2^{* *}$ \\
\hline
\end{tabular}

${ }^{\mathrm{z}}$ All values are mean $\pm \mathrm{SD}$ of triplicate determinations.

$* *$ and $*$ : Significant at $\mathrm{p}<0.001$ and $\mathrm{p}<0.005$.

used as a cosmetic ingredient, this study measured the $\mathrm{pH}$. The changes in the $\mathrm{pH}$ depending on the solvents when the extract was dissolved are presented in Table 1. The $\mathrm{pH}$ for

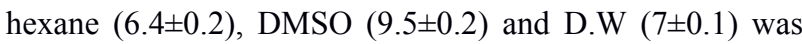
higher than the ideal acidity of skin, a pH of 5.5, but after the specimen was dissolved, the values lowered. The alkali grew weaker and the $\mathrm{pH}$ approached 5.5. The results were as follows: hexane (5.8 \pm 0.3$)$, DMSO ( $8.4 \pm 0.2)$, and D.W (6.5 \pm 0.1$)$. For Chloroform (3.2 \pm 0.4$)$, ethyl acetate (2.6 \pm 0.3$)$ and ethanol (5.3 \pm 0.2 ), after the specimen was dissolved, strong acidity changed into weak acidity as follows: chloroform (4.4 \pm 0.9$)$, ethyl acetate (3.1 \pm 0.6$)$ and ethanol (5.8 \pm 0.4$)$. Thus, it was found that solvents with different polarities have the ability to control acidity centering on a $\mathrm{pH}$ of 5.5 .

\section{UV-spectrum measurement}

In the lab values of the Commission Internationale de I'Eclairage : CIE, L indicates luminosity, a indicates colors from red to green, and $b$ indicates those from yellow to blue. In each solvent, the extract was colored red in an acid solvent such as chloroform or ethyl acetate, dark purple in higher $\mathrm{pH}$ solvents such as hexane, butanol, and ethanol, and purple in an alkali such as DMSO, and a $\mathrm{L}^{*} \mathrm{a} * \mathrm{~b} *$ value based on the colorimetry is presented in Table 2 .

The UV-spectrum of the extract in different solvents was measured between $200 \mathrm{~nm}$ and $700 \mathrm{~nm}$. It was discovered that hexane, chloroform, ethyl acetate, butanol and ethanol had similar absorption zones with the largest values at $520 \mathrm{~nm}$ and
Table 2. L-a-b value of Lithospermum erthrohizon

\begin{tabular}{cccc}
\hline & $\mathrm{L}$ & $\mathrm{a}$ & $\mathrm{b}$ \\
\hline Hexane & $61.67 \pm 0.649$ & $46.46 \pm 1.785^{* *}$ & $15.47 \pm 0.962^{* *}$ \\
Chloroform & $71.31 \pm 0.264^{* *}$ & $31.54 \pm 1.545^{* *}$ & $7.9 \pm 0.648^{* *}$ \\
E.Acetate & $64.39 \pm 0.271^{* *}$ & $44.17 \pm 0.120^{* *}$ & $14.21 \pm 0.066^{* *}$ \\
Butanol & $66.69 \pm 0.327 * *$ & $38.74 \pm 1.010^{* *}$ & $10.90 \pm 0.637^{* *}$ \\
Ethanol & $76.29 \pm 0.302^{* *}$ & $24.32 \pm 1.231^{* *}$ & $3.77 \pm 0.459$ \\
DMSO & $34.15 \pm 0.106^{* *}$ & $13.01 \pm 1.846^{*}$ & $4.52 \pm 0.259^{* *}$ \\
Water & $89.92 \pm 0.914$ & $3.20 \pm 1.065^{*}$ & $7.97 \pm 0.191^{* *}$ \\
\hline${ }^{\mathrm{z}}$ All values are mean $\pm \mathrm{SD}$ of triplicate determinations. \\
${ }^{\mathrm{y}} \mathrm{L}$ : lightness, a: redness, b: yellowness. \\
** and *: Significant at $\mathrm{p}<0.001$ and $\mathrm{p}<0.005$.
\end{tabular}

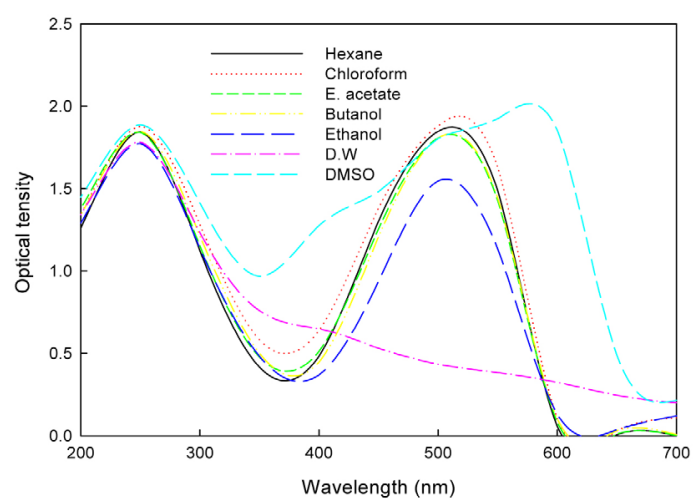

Fig. 2. UV-spectrum value of Lithospermum erythrorhizon.

$530 \mathrm{~nm}$, and DMSO had a wider absorption zone. In distilled water, the absorption for the visible light zone was not significant, but it is suggested that this is because the pigment of the extract is not water-soluble. UV-spectrum measurements are presented in Fig. 2.

\section{Electron donating ability}

In measuring the EDA, the degrees to which electrons are donated to active radicals and how strongle oxidation is inhibited are measured. Anti-oxidation is measured through the degree the dark purple color of DPPH is washed out by the polyhydroxyl aromatic compound, aromatic amine, and ascorbic acid. Electron donating ability effects in measuring the anti-oxidation activity of the $70 \%$ ethanol extract were as follows: $34.9 \% \pm 1.11$ at $62.5 \mathrm{ppm}$ and $74.47 \% \pm 0.73$ at 1000 ppm. The scavenging effects were higher in comparison at 


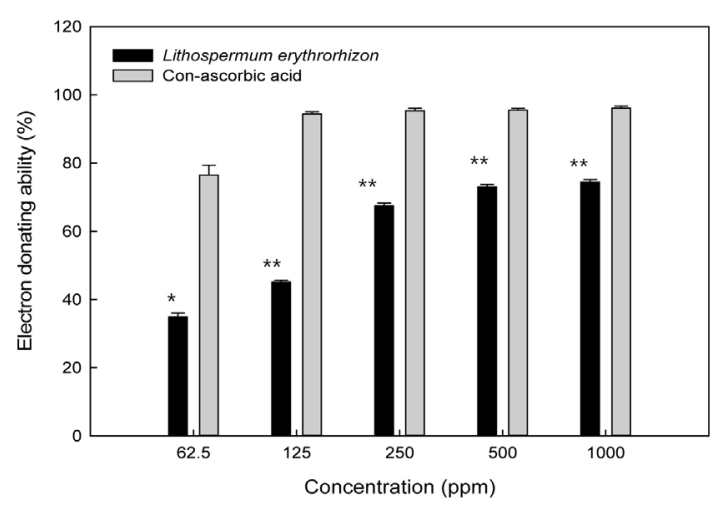

Fig. 3. Electron donating ability of the ethanol extracts from Lithospermum erythrorhizon.

The bars represent the standard deviation. Asterisk indicates a significant difference at $* * \mathrm{p}<0.001,{ }^{*} \mathrm{p}<0.005$ level.

Table3. Antioxidant activity, phenolics contents of the Lithospermum erythrorhizon studied

\begin{tabular}{|c|c|c|}
\hline & Total polyphenol(mg/g $\left.\mathrm{GAE}^{\mathrm{x}}\right)$ & DPPH $\left(\mathrm{IC}_{50}\right)(\mu \mathrm{g} / \mathrm{ml})$ \\
\hline Sample ${ }^{\mathrm{y}}$ & $51.284 \pm 2.552$ & 149.818 \\
\hline
\end{tabular}

${ }^{\mathrm{z}}$ All values are mean $\pm \mathrm{SD}$ of triplicate determinations.

${ }^{\mathrm{y}}$ Sample: experiment extract obtained $70 \%$ ethanol condition.

${ }^{\mathrm{x}} \mathrm{GAE}$ : gallic acid equivalent.

$76.48 \% \pm 2.85$ and $96.14 \% \pm 0.58$ in ascorbic acid, the control group (Fig. 3).

As one of the methods to evaluate anti-oxidation in natural substances, for an $\mathrm{IC}_{50}$ value for which a specimen concentration needed to scavenge $50 \%$ of the DPPH radical specimen, the concentration was $0.015 \%$ and the concentration was $149.8 \mu \mathrm{g} / \mathrm{ml}$. Previous studies reported that the $\mathrm{IC}_{50}$ value of ethyl acetate fraction was $122.95 \mu \mathrm{g} / \mathrm{ml}$, which was the highest value for the extract fractions for Lithospermum erythrorhizon (Kim et al., 2010) and the 70\% ethanol extract in this study showed similar results. Also, as previous studies reported that anti-oxidation of EDA had correlations with the total phenolic compounds, EDA was compared with the amount of phenolic compounds and the results are presented in Table 3. Based on a report (Tobin and Thody, 1994) that removal of reactive oxygen is effective for inhibition of pigmentation, the high reactive oxygen scavenging effects showed the possibility that the subject extract to be used as a material for whitening cosmetics.

\section{Total polyphenol compound}

A polyphenol compound, as a representative anti-oxidative material, has a phenolic hydroxyl which can be connected with protein and macromolecules, it shows different forms of bioactivity such as anti-oxidation and anti-cancer effects (Jung et al., 2004). The total amount of polyphenol compound measured with gallic acid as a standard material was $51.28 \pm$ $2.55(\mathrm{mg} / \mathrm{g})$ and Table 3 shows its relationships with the EDA. The relationship between the wave absorption of natural pigments extracted from natural material and other ingredients were examined through a UV/VIS spectrum measurement. The ethanol extract of Lithospermum erythrorhizon varies in color from red to purple depending on the solvents. Compounds with such a color must be conjugations of long-chains, have polycyclic aromatic chromophores or benzenoids with conjugating substituents, and as the polarity of solvents increases, they were observed at 400 500 nm UV Spectra in the same area where compounds such as flavones and flavonols are observed. As in Fig. 2, as all the maximum absorption frequencies ranged from 270 to $280 \mathrm{~nm}$ and from 525 to $530 \mathrm{~nm}$, at the same wavelength as napthoquinone pigment containing shikonin, a high absorption appeared.

\section{DOPA autoxidation inhibition assay (in vitro)}

When skin is exposed to ultraviolet rays, Tyrosin in pigmentation cells, which exists in the basal layer of skin, produces melanin through enzyme action of tyrosinase. Melanin which is produced excessively at this time causes pigmentary deposits such as melasma or freckles. It has been reported that effective materials which inhibit tyrosinase activity are ascorbic acid, arbutin, kojic acid, azelaic acid, and tropolone (Jung et al., 1995). Recently, experiments using extraction to search for effective naturally sourced materials which will inhibit melanin synthesis have increased. The values for tyrosinase activity inhibition within pigment cells are presented in Fig. 4. 


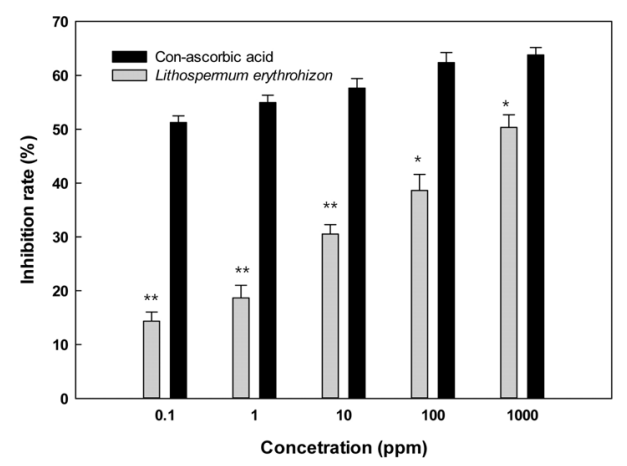

Fig. 4. DOPA autoxidation inhibition rate of the crude ethanol extracts from Lithospermum erythrorhizon. The bars represent the standard deviation. Asterisk indicates a significant difference at ${ }^{* *} \mathrm{p}<0.01,{ }^{*} \mathrm{p}<0.05$ level.

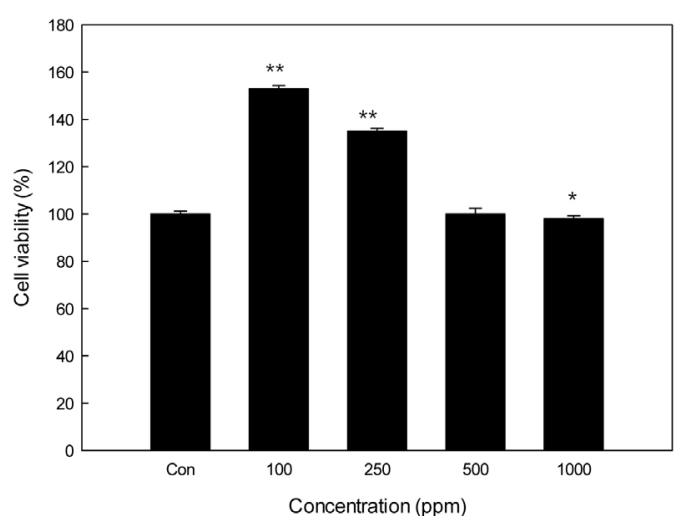

Fig. 5. Cytoxicity of the crude ethanol extracts from Lithospermum erythrorhizon.

The bars represent the standard deviation. Asterisk indicates a significant difference at ${ }^{* *} \mathrm{p}<0.001,{ }^{*} \mathrm{p}<0.005$ level.

Ascorbic acid of the control group showed more than a $50 \%$ inhibitory activity both at $0.1 \mathrm{ppm}$, the lowest concentration and 1000 ppm, the highest concentration. The extracts of Lithospermum erythrorhizon had a $16 \%$ inhibitory activity at $0.1 \mathrm{ppm}$, but had a $51 \%$ inhibitory activity at $1000 \mathrm{ppm}$. At 10 ppm, a $41 \%$ inhibitory activity appeared and when it was compared with the $30 \%$ shown by angelica anchangelica (Son et al., 2011) and the $31.8 \%$ of kousa at the same concentration, it was discovered that there is a possibility that this material can be applied for whitening cosmetics as a tyrosinase activity inhibitory ingredient. Such results showed the correlations between anti-oxidation and whitening effects in the same context as discussion of the possibility involving EDA measurement (Tobin and Thody, 1994).

\section{Measuring cytotoxicity}

The results on the survival rates discovered through the MTT assay are presented in Fig. 5. The extracts of Lithospermum erythrorhizon were treated with a macrophage (Raw 264.7) at $100,250,500$, and $1000 \mathrm{ppm}$, the cell survival rates were $153 \%$ at $100 \mathrm{ppm}, 135 \%$ at $250 \mathrm{ppm}, 100 \%$ at $500 \mathrm{ppm}$, and $98 \%$ at $1000 \mathrm{ppm}$. Proliferation of $150 \%$ cell growth occurred at $100 \mathrm{ppm}$ where the extracts were added and at the concentrations of $500 \mathrm{ppm}$ and $1000 \mathrm{ppm}$, cell growth slowed down with similar survival rates to that of the control group, but as the survival rate did not significantly slow down in comparison with that of the control group, it was suggested that it was not affected by the toxicity of the specimen.

This study measured the $\mathrm{pH}$ of Lithospermum erythrorhizon as well as the UV-spectrum, anti-oxidation ability, whitening, and cytotoxicity to discover the possibility of using the ethanol extract as an ingredient in cosmetics. As a result of the test, the following results were discovered: This material had the ability to control strongly acid and alkaline solvents centering on a $\mathrm{pH}$ of 5.5 , the most ideal $\mathrm{pH}$ for skin. The maximum absorption peak was observed between $270-280 \mathrm{~nm}$ and at $530 \mathrm{~nm}$ in the UV-spectrum, and the total amount of polyphenol compound was $51.28 \pm 2.55(\mathrm{mg} / \mathrm{g})$. Also, as the DPPH scavenging effects were $34.9 \pm 1.11$ at $62.5 \mathrm{ppm}$, in low activity, they grew greater according to the concentration of the specimen, and at $1000 \mathrm{ppm}$, the activity effects was $74.47 \% \pm 0.73$. This was $80 \%$ of that for ascorbic acid at the same concentration for an $\mathrm{IC}_{50}$ value needed to scavenge DPPH radicals, the concentration of the specimen was $0.015 \%$ and the concentration was $149.8 \mu \mathrm{g} / \mathrm{ml}$.

The tyrosinase activity inhibition value was $33 \%$ at $10 \mathrm{ppm}$ and $51 \%$ at $1000 \mathrm{ppm}$. In considering that ascorbic acid, the control group, was $58 \%$ at the same concentration, it showed high inhibitory activity. As in previous studies, as the reactive oxygen scavenging rate of EDA is higher, correlations with the whitening effects to inhibit melanin synthesis were signi- 
ficant. In the cytotoxicity test, the cell survival rate at 1000 ppm was above $98 \%$, which means there is no cytotoxicity.

To sum up the results above, the ethanol extract of Lithospermum erythrorhizon had high anti-oxidation ability and whitening effects, and has a possibility that this material can be applied as an ingredient for whitening cosmetics using natural materials as it is not involved in cytotoxicity.

\section{Literature Cited}

Bae, J.H. 2004. Antimicrobial effect of Lithospermum erythrorhizon extracts on the food-borne pathogens. Korean J. Food Sci. Technol 36(5):823-827 (in Korean).

Blois, M.S. 1958. Antioxidant determination by the use of a stable free radical. Nature 181:1199-1204.

Cha, B.C. and E.H. Lee. 2004. Antioxidant and antiinflammation activites of Prunus persica tree extracts. Korean J. Medicinal Crop Sci. 12(4):289-294 (in Korean).

Chang, J.P., E.S. Do, K.J. Kil, J.K. Yang, C.W. Yun, G.H. Lee, Y.H. Jung, Y.S. Ji, B.R. Kim and M.S. Choi. 2011. Antioxidative activity of A. victorialis var. platyphyllum extracts. J. Korean For. Soc. 100(3):408-416 (in Korean).

Cheon, S.J., M.J. Jang, W.A. Joe, B.Y. Kang, E.Y. Choi, J.S. Lee, Y.S. Jeong, Y.S. Kim, C.E. Lee, B.J. An and J.T. Lee. 2006. Antioxidant effects and application as natural ingredients of sanghwang mushroom (Phellnus linteus). J. Applied Oriental Medicine 6(1):1-6 (in Korean).

Cho, M.H., Y.S. Paik and T.R. Hahn. 1999. Physical stability of shikonin derivatives from the roots of Lithospermum erythrorhizon cultivated in Korea. J. Agric. Food Chem.47: 41174120 (in Korean).

Cho, Y.J, S.S. Chun, K.H. Lee, J.H. Kim, H.J. Kwon, B.J. An and M.U. Kim. 2006. Screening of the antimicrobial activity against Helicobacter pylori and antioxidant by extracts from mulberry fruits (Morus alba L.). J. Korean Soc. Food Sci. Nutr. 35(1):15-20 (in Korean).

Choi, S.J., Y.S. Lee, J.K. Kim, J.K. Kim and S.S. Lim. 2010. Physiological activities of extract from edible mushrooms. J. Korean Soc. Food Sci. Nutr .39(8):1087-1096 (in Korean).

Ha, B.J. 1999. Cosmetic Science. SooMoon Publishing. Co., Seoul, Korea. pp. 76-82.

Ju, J.H., H.H. Cho and Lee, Y.S. 2010. Progress on phytochemical and atopic dermatitis-related study of the root of Lithospermum erythrorhizon. Kor. J. Pharmacogn. 41(2):73-
88 (in Korean).

Jung, M.S., G.S. Lee and H.J. Chae. 2004. In vitro biological activity assay of ethanol extract of radish. J. Korea. Soc. Appl. Biol Chem. 47: 67-71 (in Korean).

Jung, S.W., N.K. Lee, S.J. Kim and D.S. Han. 1995. Screening of tyrosinase inhibitor from plants. Kor. J. Food Sci. Technol. 27:891-896 (in Korean).

Kim, J.S. and M.H. Kang. 2010. Antioxidant activity of solvent fractions from cultivated and wild gromwell. J. Korean Soc. Food Sci. Nutr. 39(6):789-795 (in Korean).

Kim, Y.J., J.A. Jeong, S.H. Kwon and C.H. Lee. 2008. Comparison of biological activities of extracts from different parts and solvent fractions in Cornus kousa buerg. Korean J. Plant Res. 21(1):28-35 (in Korean).

Lee, J.Y. and B.J. An. 2010. Anti-oxidant and anti-inflammation activities of Prunus persica Flos. Kor. J. Appl. Biol. Chem. 53(3):162-169 (in Korean).

Lee, K.S., D.K. Ahn, M.K. Shin and C.M. Kim. 1998. Encyclopedia of Oriental Herbal Medicine. Jungdam Publishing Co., Seoul, Korea. pp. 4657-4663.

Lee, S.H., S.K. An and S.K. Jung. 2004. Skin Berrier. Lyeomoonkag, Seoul, Korea. pp. 40-49.

Moon, J.Y., E.Y. Yim, G.P. Song, N.H. Lee and C.G. Hyun. 2010. Screening of elastase and tyrosinase inhibitory activity from Jeju Island plants. EurAsian J. BioSci. 4:41-53.

Ryu, E.J. and S.H. Cho. 2004. Antimicrobial characteristics and safety test of gardenia jasminoides Extract. J. Agriculture \& Life Science 38(4)11-19 (in Korean).

Sim,E.K. and K.R. Kim. 2008. Consumer's preference and determinants of purchase of cosmeceutical products. J. Kor. Cosm. 14(4):1264-1279 (in Korean).

Son, H.U., D.Y. Nam, M.A. Kim, Y.S. Cha, J.M. Kim, Y.K. Shin and S.H. Lee. 2011. Inhibitory effect of Angelica keiskei extracts on melanogenesis. Korean J. Food Preserv. 18(6): 998-1001.

Swan, T., W.E. Hillis and M. Ortega. 1959. Phenolic constituents of ptunus domeatica, I. Quantitative analysis of phenolic constituents. J. Sci. Food Agric. 10:83-88.

Tobin, D. and A.J. Thody. 1994. The superoxide anion may mediate short but not long term effects of ultraviolet radiation on melanogenesis. Exp. Dermatol. Jun. 3(3):99-105.

Yun, K.J., D.H. Kim, J.H. Lyu and C.S. Yook. 1999. Studies on the constituents and their antibacterial effect of the root of Lithospermum erythrorhizon. Bull. K.H. Pharma. Sci. 27: 31-36 (in Korean).

(Received 19 March 2013 ; Revised 20 June 2013 ; Accepted 21 June 2013) 